\title{
Article \\ Prevalence of Advanced Parkinson's Disease in Patients Treated in the Hospitals of the Spanish National Healthcare System: The PARADISE Study
}

\author{
Juan Carlos Martínez-Castrillo 1,*(D), Pablo Martínez-Martín ${ }^{2}$, Ángel Burgos ${ }^{3}$, Gloria Arroyo ${ }^{4}$, Natalia García ${ }^{4}$, \\ María Rosario Luquín ${ }^{5}$ and José Matías Arbelo ${ }^{6}$ \\ 1 Departamento de Neurología, Hospital Universitario Ramón y Cajal, Ctra. de Colmenar Viejo, km. 9100, \\ 28034 Madrid, Spain \\ 2 Centro de Investigación Biomédica en Red Sobre Enfermedades Neurodegenerativas (CIBERNED), Instituto \\ de Salud Carlos III (ISCIII), Calle Valderrebollo, 5, 28031 Madrid, Spain; pmm650@hotmail.com \\ 3 Pivotal, S.L.U. Calle Gobelas, 19, 28023 Madrid, Spain; Angel.Burgos@pivotalcr.com \\ 4 AbbVie Spain S.L.U. Avenida De Burgos 91, 28050 Madrid, Spain; gloria.arroyo@abbvie.com (G.A.); \\ natalia.garcia@abbvie.com (N.G.) \\ 5 Servicio de Neurología, IdiSNA, Clínica Universidad de Navarra (CUN), Av. de Pío XII, 36, \\ 31008 Pamplona, Spain; rluquin@unav.es \\ 6 Servicio de Neurología, Hospital Universitario San Roque Las Palmas, Calle Dolores de la Rocha 5, \\ 35001 Las Palmas de Gran Canaria, Spain; jmarbelo@gmail.com \\ * Correspondence: jmcastrillo@salud.madrid.org; Tel.: +34-91-336-8397
}

\section{check for}

updates

Citation: Martínez-Castrillo, J.C.; Martínez-Martín, P.; Burgos, Á.; Arroyo, G.; García, N.; Luquín, M.R.; Arbelo, J.M. Prevalence of Advanced Parkinson's Disease in Patients Treated in the Hospitals of the Spanish National Healthcare System: The PARADISE Study. Brain Sci. 2021, 11, 1557. https://doi.org/10.3390/ brainsci11121557

Academic Editor: Andrea Loftus

Received: 29 September 2021

Accepted: 17 November 2021

Published: 24 November 2021

Publisher's Note: MDPI stays neutral with regard to jurisdictional claims in published maps and institutional affiliations.

Copyright: (C) 2021 by the authors Licensee MDPI, Basel, Switzerland. This article is an open access article distributed under the terms and conditions of the Creative Commons Attribution (CC BY) license (https:// creativecommons.org/licenses/by/ $4.0 /)$.
Abstract: Background: Advanced Parkinson's disease (APD) has been recently defined as a stage in which certain symptoms and complications are present, with a detrimental influence on the overall patient's health conditions and with a poor response to conventional treatments. However, historically, the term APD has been controversial, thus consequently, APD prevalence has not been previously studied. Objectives: The main objective was to determine the prevalence of APD in patients diagnosed with idiopathic PD in hospitals of the Spanish National Healthcare System. Secondary objectives were the prevalence and incidence of $\mathrm{PD}$ and the clinical and sociodemographic characteristics and quality of life of patients with APD or non-APD. Methods: This was a noninterventional, cross-sectional, multicenter, national study in the hospital setting. Results: The study population included 929 patients with PD (mean age $71.8 \pm 10.1$ years; $53.8 \%$ male) and a mean time since diagnosis of $6.6 \pm 5.4$ years. At the time of diagnosis, 613 patients $(66.06 \%)$ reported having had premotor symptoms. The Hoehn and Yahr stage was 1 in 15.7\% of the patients, 2 in $42.8 \%, 3$ in $30.1 \%, 4$ in $9.9 \%$, and 5 in $1.4 \% ; 46.9 \%$ of the patients had comorbidities (mean age-adjusted Charlson comorbidity index $3.5 \pm 1.7$; median 10-year survival 77\%) and the mean 8-item Parkinson's Disease Quality of Life Questionnaire was $27.8 \pm 20.5$. We found an APD prevalence of $38.21 \%$ (95\%CI: $35.08-41.42 \%$ ), a PD prevalence of 118.4 (95\%CI: 117.3-119.6), and a PD incidence of 9.4 (95\%CI: 5.42-13.4) all per 100,000 population. Among the APD population, a $15.2 \%$ were receiving some form of therapy for advanced stages of the disease (deep brain stimulation, levodopa/carbidopa intestinal gel, or apomorphine subcutaneous infusion). Conclusions: The percentage of patients with APD in the hospitals of the Spanish National Healthcare System was 38.2\%.

Keywords: incidence; Advanced Parkinson's disease; prevalence; idiopathic Parkinson's disease; quality of life

\section{Introduction}

Parkinson's disease (PD) is one of the most prevalent neurodegenerative disorders in the world [1] and a growing source of disability globally [2]. Prevalence rates for patients with PD vary across studies and countries; however, a meta-analysis published in 2014 estimated a prevalence rate of PD worldwide of 300 patients per 100,000 population [3]. 
Parkinson's disease is a progressive disease; most patients progress to an advanced stage after 7-10 years form diagnosis [4]. In this advanced stage, the disease is highly disabling, has a complex management, impacts seriously patient's quality of life (QoL), and increases healthcare system expenses. Typically, advanced Parkinson's disease (APD) patients develop motor fluctuations, dyskinesias, and non-motor symptoms within 3 to 5 years of starting dopaminergic therapy, and these motor complications could be, at this stage, refractory to treatment. Conversely, comorbidities within this population, arising independently of the underlying disease, such as neoplasms [5], may increase the burden of the social and Healthcare System. However, despite this clinical and administrative relevance, the prevalence of advanced PD is unknown, mainly because of the absence of an APD-specific definition. Sizing the number of patients at this advance stage of the disease should help the health authorities to reorganize resources, if necessary.

In this epidemiologic study, the main objective was to determine the prevalence of APD in patients diagnosed with idiopathic PD in hospitals of the Spanish National Healthcare System. Secondary objectives included the assessment of the prevalence and incidence of PD in hospitals of the Spanish National Healthcare System, the description of the clinical and sociodemographic characteristics of patients with $\mathrm{PD}$, and the comparison of the QoL of patients with APD and non-APD (nAPD).

\section{Materials \& Methods}

\subsection{Study Design}

This was a non-interventional, cross-sectional, multicenter, national study carried out in Spain from April 2017 through January 2019 at 21 participant clinical sites. The study population consisted of patients with idiopathic PD according to the UK Parkinson's Disease Society Brain Bank criteria [6] at the participant sites. These sites were randomly selected from the list of the 234 Spanish public hospitals and stratified according to the type of hospital, considering the total population covered by the site. In Spain, based on the time and resources dedicated to PD, three types of neurology services at the hospital level can be described (in descending order): (1) services with a movement disorders unit; (2) services with PD dedicated clinics; (3) services with general neurology clinics. PD dedicated clinics are general neurology services with at least one neurologist attending a specific clinic for PD with some regularity. Out of a total population of 46,423,064 inhabitants in Spain at the time of the study design [7], the Spanish public hospitals covered 42,501,454 Spanish people: $8,798,286(20.7 \%)$ at hospitals with movement disorder units; $17,076,616(40.2 \%)$ at hospitals with PD dedicated clinics; 16,626,552 (39.1\%) at hospitals with general neurology services [8]. Subsequently, to guarantee the representativity of the sample, approximately $20 \%$ of the selected patients should be treated at hospitals with movement disorder units (MDUs), 40\% at hospitals with PD dedicated clinics, and 40\% at hospitals with general neurology services. When a center denied its participation, it was randomly substituted by another with the same characteristics. At each center, the selection of the patients was performed using systematic random sampling. The stratified random sampling of sites, the determination of patient sample size, and the estimation $( \pm 3)$ of the prevalence followed the methods as described in Levy and Lemeshow [9]. The random sampling (of both centers and patients) guaranteed that patients with PD entering the study were representative of the whole Spanish PD population. The APD diagnosis was made according to the neurologist's criteria, which was considered the gold standard, and with the Questionnaire for Advanced Parkinson's Disease (CDEPA), a tool that was developed to assist in the diagnosis of APD [10]. This tool was developed following the Delphi method; APD was defined as a stage of PD in which certain symptoms and complications are present, with a detrimental influence on the overall patient's health conditions and poor response to conventional treatment [11]. In case of a discrepancy, the neurologist's criteria prevailed. Patients provided signed informed consent to participate in the study. Patients unable to provide signed informed consent and whose caregiver was unwilling to provide written informed consent on their behalf were excluded. 
All patients with PD from the selected hospitals were registered for determining the prevalence and the incidence of PD. Patients with APD were identified among those randomly selected. For patients who chose not to participate in the study, the reason was recorded, and other patients were recruited instead. Because the frequency of visits differs across hospitals (from 3 times per year to once per year), the study recruitment period was established in 1 year to ensure that all patients being cared for in a particular center were registered. In few centers in which the recruitment period was shorter than 12 months, PD prevalence and incidence were annualized and weighted according to the number of months of recruitment to make them comparable.

The study was conducted in accordance with ethical principles that have their origin in the Declaration of Helsinki. The study was approved by the Spanish Agency of Medicines and Medical Devices and the Ethics Committees of all the participant hospitals.

\subsection{Variables}

Sociodemographic data and clinical variables (age, sex, occupational status, PD disease duration, Hoehn and Yahr (H\&Y) stage at the time of PD diagnosis and at the time of patient inclusion in the study, pre-motor symptoms, and concurrent comorbidities) were obtained from computerized hospital records, patient medical records, or discharge reports. APD diagnosis was established according to the criteria above mentioned. The percentage of patients with APD was calculated by dividing the total number of patients with APD per the total number of patients with PD recruited in the study and multiplying by 100 . The following equation was used to estimate PD annual prevalence:

(Total number of patients with PD in a 12-month period/total number of inhabitants covered by the sites) $\times 100,000$.

The following equation was used to estimate PD annual incidence:

(Total number of new cases of PD in a 12-month period/total number of inhabitants covered by the sites) $\times 100,000$.

Ten-year survival was estimated using the Charlson comorbidity index [12]. Patient QoL was evaluated using the 8-item Parkinson's Disease Quality of Life Questionnaire (PDQ-8; the score was standardized on a scale of 0 to 100) [13]. Additionally, the H\&Y stage in ON or OFF state was assessed using the H\&Y rating scale [14].

\subsection{Statistical Analysis}

Sample size calculation is presented as Supplementary Material.

Descriptive statistics (mean, standard deviation, median, percentage, and 95\% confidence interval) were used as needed. For comparisons, and considering their assumptions for use, Student's $t$ or Wilcoxon-Mann-Whitney tests were applied.

Chi-square test or Fisher exact test were used, as applicable to assess possible association between qualitative variables. McNemar's test or Cochran's $Q$ test were used for paired data. Unweighted kappa statistic was used to assess the concordance between the neurologist's criteria and the CDEPA identifying APD patients. Logistic regression was performed to ascertain the effects of the presence of CDEPA APD definitory symptoms, age, sex, age-adjusted Charlson comorbidity index, and H\&Y stage on the likelihood that APD patients receive a device aided therapy (DAT), that is, deep brain stimulation, levodopa/carbidopa intestinal gel, or apomorphine subcutaneous infusion. A two-tailed $p<0.05$ was used to denote statistically significant differences. All analyses were performed using SAS ${ }^{\circledR}$ v9.4 software (SAS Institute Inc., Cary, NC, USA).

\section{Results}

Nine hundred and fifty-five patients were invited to participate in the study, of whom $26(2.8 \%)$ did not provide consent for study participation. Thus, the study population included 929 patients: 227 (24.4\%) in hospitals with a movement disorder unit, 297 (32.0\%) in hospitals with a PD dedicated clinic and $405(43.6 \%)$ in hospitals with a general neurology 
service. Clinical and sociodemographic characteristics of patients at the time of study inclusion according hospital type are shown in Table 1.

Among the 929 patients, 355 were identified as having APD. Thus, the prevalence of APD in patients with PD attended at hospitals of the Spanish National Health System was 38.2\% (95\%CI: 35.1-41.4\%). No statistically significant differences were seen in the percentages of patients with APD among those patients with PD attended at hospitals with general neurology services (38.1\% (95\%CI: 33.3-42.9\%)), with PD dedicated clinics (37.7\% (95\%CI: $32.2-43.5 \%))$, and with movement disorder units (39.2\% (95\%CI: $32.8-45.9 \%)$ ) $(p=0.94)$.

The concordance between the neurologist's criteria and the CDEPA identifying patients with APD was $k=0.94$ (95\%CI: 0.92-0.96; $p<0.0001)$. A high level of concordance was also found between the neurologist's criteria and the CDEPA when concordance was assessed according to the type of hospital, as follows: hospitals with general neurology services $\kappa=0.90$ (95\%CI: 0.86-0.94; $p<0.0001$ ), with PD dedicated clinics $\kappa=0.97$ (95\%CI: $0.94-1.00 ; p<0.0001$ ), and with movement disorder units $\kappa=0.97$ (95\%CI: 0.94-1.00; $p<0.0001)$.

Differences were found when comparing the sociodemographic and clinical characteristics of patients with nAPD and APD (Table 2). At the time of inclusion in the study, mean age was higher in patients with APD $(73.7 \pm 10.0$ years $)$ than in patients with nAPD (70.7 \pm 10.0 years; $p<0.0001)$, a higher percentage of men $(56.8 \%)$ was found in patients with nAPD than in those with APD $(49.0 \% ; p=0.0208)$, and a higher H\&Y stage evaluated in patients considered $\mathrm{ON}$ at the time of diagnosis was found in patients with APD vs. nAPD $(p<0.0001)$. Additionally, a higher percentage of patients with APD $(83.0 \%)$ than nAPD $(72.3 \%)$ reported having had premotor symptoms $(p=0.0007)$, mean age-adjusted Charlson comorbidity index was significantly higher in patients with APD $(3.77 \pm 1.78)$ than in those with nAPD $(3.27 \pm 1.58 ; p<0.0001)$, and the median 10-year survival probability was significantly lower in patients with APD (53\%) than in those with nAPD (77\%; $p<0.0001)$.

Reasons for not having started a DAT among patients with APD also differed according to hospital type ( $p=0.028$; Figure 1$)$. Patients with a disease duration of $\geq 10$ years were 6.77 times (95\%CI: 2.83-16.17) more likely to receive a DAT than patients with a disease duration of $<10$ years; patients with motor fluctuations with an OFF time of $>25 \%$, with limitation to perform basic activities but without requiring help, were 2.11 times ( $95 \% \mathrm{CI}$ : 1.01-4.41) more likely to receive a DAT than patients who did not have motor fluctuations with an OFF time of $>25 \%$, with limitation to perform basic activities but without requiring help. Increasing age was also associated with an increased likelihood of receiving a DAT (odds ratio 1.10; 95\%CI: 1.06-1.14).

The QoL of patients with PD, assessed with the PDQ-8 at the time of study inclusion, showed a mean score of $27.8 \pm 20.5$. No statistically significant differences were found when mean PDQ-8 scores obtained in patients receiving care from different hospital types were compared. However, a statistically significant worsening in QoL was found in patients with APD (Figure 2). The mean PDQ-8 score in patients with nAPD was $19.2 \pm 15.3$ versus $41.7 \pm 20.3$ in APD patients $(p<0.0001)$. This difference was also observed in all subdomains of the questionnaire. Among the APD population, there were no significant differences in PDQ-8 scores between patients treated with a DAT compared with those not treated with a DAT ( $43.0 \pm 22.4$ vs. $41.5 \pm 19.9$, respectively; $p=0.62)$. However, there were differences in PDQ-8 scores between the different DAT untreated patient populations based on the reasons for not having started a DAT (in order of increasing score): $34.9 \pm 17.5$ (clinically stable), $<39.2 \pm 19.3$ (option not yet considered), $<42.7 \pm 21.1$ (on waiting list), $<43.1 \pm 16.2$ (treatment rejected by the patient), $<49.5 \pm 12.3$ (other reasons), and $<57.0 \pm 24.0$ (DAT contraindicated), $p<0.0001$. 
Table 1. Clinical and sociodemographic characteristics of patients at the time of study inclusion according hospital type.

\begin{tabular}{|c|c|c|c|c|c|}
\hline Characteristic & $\begin{array}{l}\text { Hospital with General } \\
\text { Neurology Service } \\
(n=405)\end{array}$ & $\begin{array}{l}\text { Hospital with Parkinson's } \\
\text { Disease Dedicated Clinic } \\
(\mathrm{n}=297)\end{array}$ & $\begin{array}{l}\text { Hospital with } \\
\text { Movement Disorder Unit } \\
(\mathrm{n}=227)\end{array}$ & $\begin{array}{c}\text { Total } \\
(\mathrm{n}=929)\end{array}$ & $p$ Value \\
\hline \multicolumn{6}{|l|}{ Age, years } \\
\hline Median & 75 & 70 & 72 & 73 & \multirow{3}{*}{$<0.0001$} \\
\hline Q1-Q3 & $68-81$ & $63-77$ & $65-80$ & $65-80$ & \\
\hline Min-Max & $36-92$ & $38-90$ & $42-93$ & $36-93$ & \\
\hline \multicolumn{6}{|l|}{ Sex, male, $\%$ a } \\
\hline $50-59$ & 66.7 & 82.6 & 48.3 & 65.9 & $<0.001$ \\
\hline $60-69$ & 43.3 & 50.0 & 57.7 & 50.3 & 0.13 \\
\hline $70-79$ & 61.2 & 50.6 & 50.0 & 53.9 & 0.2 \\
\hline $80-90$ & 56.8 & 44.3 & 53.1 & 51.4 & 0.19 \\
\hline $\begin{array}{c}\text { Cared for at the habitual hospital, } \% \\
\text { Occupational status, } \%\end{array}$ & 99.0 & 99.3 & 96.0 & 98.4 & 0.011 \\
\hline Medical leave due to PD & 1.48 & 3.70 & 5.29 & 3.12 & \multirow{6}{*}{-} \\
\hline Medical leave due to other reason & 0.74 & 1.35 & 0.00 & 0.75 & \\
\hline Employed & 5.93 & 10.1 & 11.9 & 8.72 & \\
\hline Retired & 74.6 & 56.9 & 71.8 & 68.2 & \\
\hline Has never worked & 12.8 & 19.9 & 10.1 & 14.4 & \\
\hline Other/unknown & 3.07 & 7.07 & 0.00 & 3.88 & \\
\hline \multicolumn{6}{|l|}{ Disease duration } \\
\hline Mean $\pm S D$, years & $6.07 \pm 5.42$ & $7.51 \pm 6.18$ & $6.40 \pm 5.47$ & $6.61 \pm 5.72$ & \multirow{3}{*}{0.006} \\
\hline$<10$ years, $\%$ & 77.0 & 70.7 & 74.0 & 74.2 & \\
\hline$\geq 10$ years, $\%$ & 23.0 & 29.3 & 26.0 & 25.7 & \\
\hline \multicolumn{6}{|l|}{ Hoehn and Yahr stage in ON state, $\mathrm{n}(\%)$} \\
\hline 1 & $74(19.7)$ & $47(16.9)$ & $14(6.80)$ & $135(15.7)$ & \multirow{5}{*}{0.002} \\
\hline 2 & $153(40.8)$ & $112(40.3)$ & $103(50.0)$ & $368(42.8)$ & \\
\hline 3 & $102(27.2)$ & $96(34.5)$ & $61(29.6)$ & $259(30.1)$ & \\
\hline 4 & $40(10.7)$ & $20(7.2)$ & $25(12.1)$ & $85(9.90)$ & \\
\hline 5 & $6(1.60)$ & $3(1.08)$ & $3(1.46)$ & $12(1.40)$ & \\
\hline
\end{tabular}


Table 1. Cont.

\begin{tabular}{|c|c|c|c|c|c|}
\hline Characteristic & $\begin{array}{l}\text { Hospital with General } \\
\text { Neurology Service } \\
(n=405)\end{array}$ & $\begin{array}{l}\text { Hospital with Parkinson's } \\
\text { Disease Dedicated Clinic } \\
(\mathrm{n}=297)\end{array}$ & $\begin{array}{l}\text { Hospital with } \\
\text { Movement Disorder Unit } \\
(\mathrm{n}=227)\end{array}$ & $\begin{array}{c}\text { Total } \\
(\mathrm{n}=929)\end{array}$ & $p$ Value \\
\hline \multicolumn{6}{|l|}{ Premotor symptom, ${ }^{\mathrm{b}} \mathrm{n}(\%)$} \\
\hline REM sleep disorder & $94(29.6)$ & $65(28.9)$ & $60(30.9)$ & $219(29.7)$ & 0.09 \\
\hline Depression & $143(42.9)$ & $96(39.2)$ & $74(38.3)$ & $313(40.6)$ & 0.71 \\
\hline Constipation & $155(59.2)$ & $103(44.8)$ & $102(54.8)$ & $360(49.7)$ & 0.14 \\
\hline Concomitant disease, $\%$ & 46.9 & 34.3 & 35.7 & 40.1 & 0.001 \\
\hline Mean \pm SD & $3.81 \pm 1.74$ & $3.01 \pm 1.45$ & $3.43 \pm 1.71$ & $3.46 \pm 1.68$ & \\
\hline Median & 4 & 3 & 3 & 3 & $<0.0001$ \\
\hline Q1-Q3 & $3-5$ & $2-4$ & $2-4$ & $2-4$ & \\
\hline Min-Max & $0-11$ & $0-7$ & $0-10$ & $0-11$ & \\
\hline \multicolumn{6}{|l|}{ 10-year survival probability, \% } \\
\hline Mean \pm SD & $54 \pm 31$ & $69 \pm 27$ & $62 \pm 30$ & $61 \pm 30$ & \\
\hline Median & 53 & 77 & 77 & 77 & $<0.0001$ \\
\hline Q1-Q3 & $21-77$ & $53-90$ & $53-90$ & $53-90$ & \\
\hline$\widehat{\operatorname{Min}}-\widehat{M a x}$ & 0-98 & $0-98$ & $0-98$ & 0-98 & \\
\hline
\end{tabular}

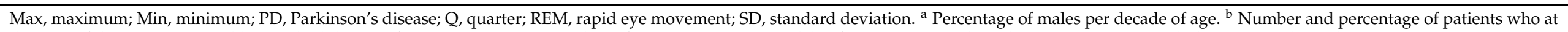
the time of diagnosis reported having had the specific premotor symptom. This information was not available for 123 patients; thus, these patients were excluded. ${ }^{c}$ Age-adjusted. 
Table 2. Clinical and sociodemographic characteristics of patients with non-APD and APD, according to hospital type.

\begin{tabular}{|c|c|c|c|c|c|c|c|c|c|}
\hline \multirow[b]{2}{*}{ Characteristic } & \multicolumn{2}{|c|}{$\begin{array}{c}\text { Hospital with General } \\
\text { Neurology Service } \\
(n=405)\end{array}$} & \multicolumn{2}{|c|}{$\begin{array}{l}\text { Hospital with Parkinson's } \\
\text { Disease Dedicated Clinic } \\
(\mathrm{n}=297)\end{array}$} & \multicolumn{2}{|c|}{$\begin{array}{c}\text { Hospital with Movement } \\
\text { Disorder Unit } \\
(\mathrm{n}=227)\end{array}$} & \multirow{2}{*}{$\begin{array}{c}\text { Total } \\
\text { Non-APD } \\
(\mathrm{n}=574)\end{array}$} & \multirow[b]{2}{*}{$\begin{array}{c}\text { Total APD } \\
(\mathrm{n}=355)\end{array}$} & \multirow{2}{*}{$p$ Value ${ }^{a}$} \\
\hline & $\begin{array}{c}\text { Non-APD } \\
(\mathrm{n}=251)\end{array}$ & $\begin{array}{c}\text { APD } \\
(\mathrm{n}=154)\end{array}$ & $\begin{array}{c}\text { Non-APD } \\
(\mathrm{n}=185)\end{array}$ & $\begin{array}{c}\text { APD } \\
(\mathrm{n}=112)\end{array}$ & $\begin{array}{c}\text { Non-APD } \\
(n=138)\end{array}$ & $\begin{array}{c}\text { APD } \\
(n=89)\end{array}$ & & & \\
\hline Age, mean $\pm S D$, years & $72.2 \pm 9.8$ & $75.6 \pm 10.0$ & $68.0 \pm 9.9$ & $71.7 \pm 9.2$ & $71.4 \pm 9.9$ & $71.4 \pm 9.9$ & $70.7 \pm 10.0$ & $73.7 \pm 10.0$ & $<0.0001$ \\
\hline Sex, female, $\%$ & 43.8 & 53.2 & 41.1 & 48.2 & 44.9 & 50.6 & 43.2 & 51.0 & 0.021 \\
\hline \multicolumn{10}{|l|}{ Occupational status, $\%$} \\
\hline Medical leave due to PD & 0.80 & 2.60 & 3.78 & 3.57 & 3.62 & 7.87 & 2.44 & 4.23 & \multirow{6}{*}{-} \\
\hline Employed & 7.97 & 2.60 & 14.6 & 2.68 & 16.7 & 4.49 & 12.2 & 3.10 & \\
\hline Unemployed & 1.20 & 0.00 & 0.00 & 2.68 & 0.72 & 1.12 & 0.70 & 1.13 & \\
\hline Retired & 72.9 & 77.3 & 53.5 & 62.5 & 73.2 & 69.7 & 66.7 & 70.7 & \\
\hline Has never worked & 12.75 & 13.0 & 17.8 & 23.2 & 5.80 & 16.8 & 12.7 & 17.2 & \\
\hline Other/unknown & 3.59 & 3.90 & 8.64 & 4.47 & 0.00 & 0.00 & 4.35 & 3.10 & \\
\hline Disease duration, mean $\pm S D$, years & $3.92 \pm 3.70$ & $9.59 \pm 5.95$ & $4.69 \pm 3.99$ & $12.2 \pm 6.35$ & $3.37 \pm 2.98$ & $11.1 \pm 5.1$ & $4.04 \pm 3.67$ & $10.8 \pm 6.0$ & $<0.0001$ \\
\hline Hoehn \& Yahr stage in ON state ${ }^{b}$, median & 2 & 3 & 2 & 3 & 2 & 3 & 2 & 3 & $<0.0001$ \\
\hline \multicolumn{10}{|l|}{ Premotor symptom at diagnosis ${ }^{c}, \%$} \\
\hline Hyposmia & 36.6 & 39.2 & 36.6 & 26.4 & 28.9 & 28.8 & 27.9 & 21.5 & $<0.0001$ \\
\hline Depression & 37.1 & 53.3 & 36.0 & 45.7 & 30.7 & 52.2 & 30.7 & 38.7 & $<0.0001$ \\
\hline Constipation & 40.6 & 68.2 & 39.0 & 56.6 & 47.1 & 69.2 & 34.7 & 45.8 & $<0.0001$ \\
\hline Concomitant disease, $\%$ & 45.0 & 50.0 & 34.0 & 34.8 & 36.2 & 34.8 & 39.4 & 41.4 & 0.54 \\
\hline Charlson comorbidity index $\mathrm{d}$, mean $\pm \mathrm{SD}$ & $3.60 \pm 1.68$ & $4.15 \pm 1.78$ & $2.84 \pm 1.39$ & $3.29 \pm 1.52$ & $3.25 \pm 1.52$ & $3.71 \pm 1.95$ & $3.27 \pm 1.58$ & $3.77 \pm 1.78$ & $<0.0001$ \\
\hline 10-year survival probability, median, \% & 53 & 53 & 77 & 77 & 77 & 77 & 77 & 53 & $<0.0001$ \\
\hline APD prevalence, relative frequency $\%$ & 61.9 & 38.1 & 62.3 & 37.7 & 60.8 & 39.2 & 61.8 & 38.2 & NA \\
\hline
\end{tabular}

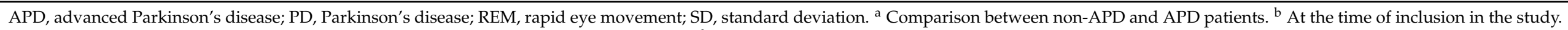

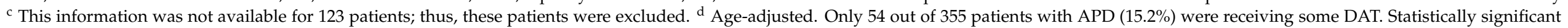

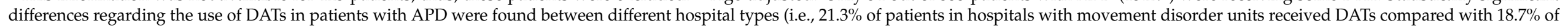

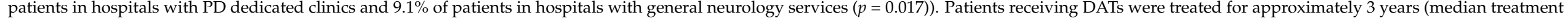
duration 3.0 years (Q1,Q3: 2.0,4.0 years)). 
Patients with APD not on DAT $(n=301)$

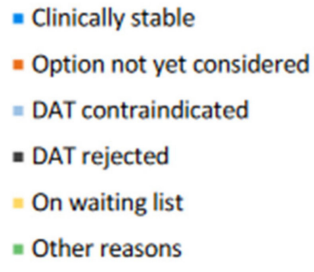

Hospital with movement

disorder unit $(n=70)$

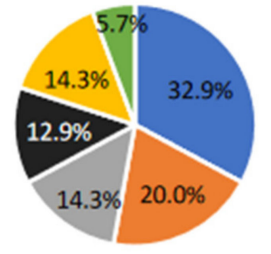
Hospital with Parkinson's disease dedicated clinic $(n=91)$

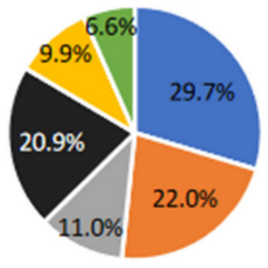

Hospital with general neurology service $(n=140)$

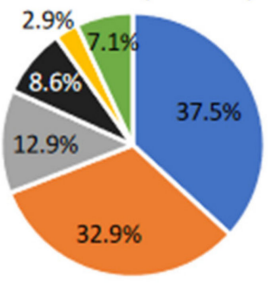

Figure 1. Reasons why patients with ADP were not on a DAT. ADP, advanced Parkinson's disease; DAT, device-aided therapy. Statistically significant differences among hospital types $(p=0.028)$.

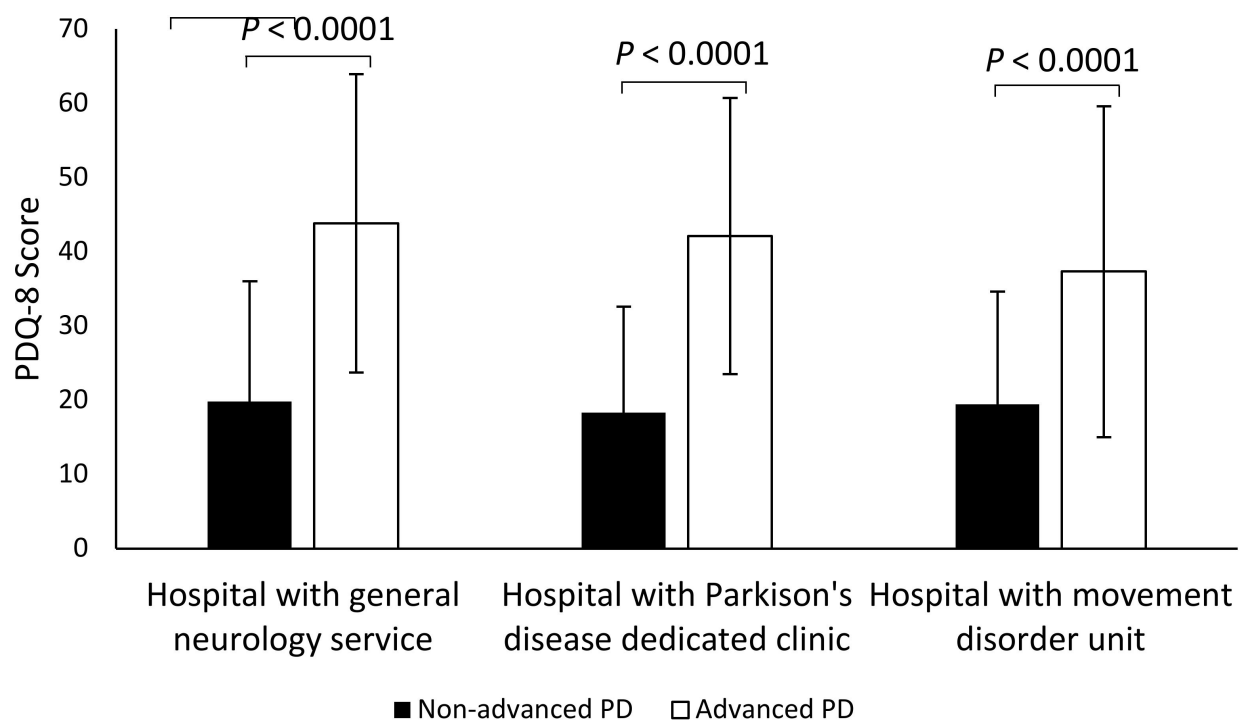

Figure 2. Quality of life of patients with advanced PD and non-advanced PD according to hospital type. PD, Parkinson's disease; PDQ-8, 8-item Parkinson's disease quality of life questionnaire. Bars represent mean $\pm \mathrm{SD}$. 
The prevalence of patients diagnosed with PD at hospitals of the Spanish National Healthcare System was 118.4 patients (95\%CI: 117.3-119.6) per 100,000 population. The annual incidence of patients with PD at hospitals of the Spanish National Healthcare System was 9.4 patients (95\%CI: 5.42-13.4) per 100,000 population.

\section{Discussion}

In this study, the percentage of patients with APD among 929 patients with PD cared for in the hospitals of the Spanish National Healthcare System was 38.2\%. This percentage was slightly lower than the $51.3 \%$ found in the OBSERVE-PD study that was a crosssectional, observational, multicenter, multicountry study carried out in 128 movement disorder centers from 18 countries involving 2615 patients [15]. In the OBSERVE-PD study, the percentages of patients with APD varied regionally and ranged from $24 \%$ to $82 \%$; this broad range could reflect differences between countries or study populations. Our study was conducted in a single country, and patients and hospitals were randomly selected; thus, the sample of participant patients were representative of the Spanish PD patient population. The fact that the sites participating in the OBSERVE-PD study were movement disorder centers does not seem to explain the higher percentages of patients with APD found in that study, as we found no significant differences between the different hospital types. Clinical and sociodemographic differences between patients with APD and nAPD were found in both the OBSERVE-PD and PARADISE studies. To the best of our knowledge, no other studies have been published analyzing the prevalence of APD and the clinical and sociodemographic characteristics of these patients.

In our study, a higher proportion of men was found among patients with nAPD; however, patient age, disease duration, H\&Y stage, proportion of patients with premotor symptoms at diagnosis, and age-adjusted Charlson comorbidity index were higher and 10-year survival probability was lower among patients with APD. In the OBSERVE-PD study, patients with APD had a higher disease duration, needed more caregiver support, presented with more motor fluctuations, and had a higher score in the Unified Parkinson's Disease Rating Scale II, III, and V than patients with nAPD [15]. Notably, the percentage of patients receiving some of the therapies considered for APD was significantly lower in our study than in the OBSERVE-PD (15.2\% vs. $44 \%$, respectively). In order to improve patient's care, this data deserves particular focus and reasons need to be analyzed. Problems such as availability of DAT, lack of prescription for some other reason or difficulties to identify DAT candidates by the neurologist could be some of them.

The QoL was significantly worse among patients with APD compared with those with nAPD in our study, with PDQ-8 scores of 41.7 and 19.2, respectively. These results were quite similar to those in the OBSERVE-PD study, where PDQ-8 scores were 36.6 and 20.7 in patients with APD and nAPD, respectively [15]. No significant differences in the QoL of patients cared for in different types of hospitals were found in our study. However, surprisingly, QoL was not different between APD DAT-treated patients and APD DAT-nontreated patients, although the three current DAT have demonstrated significant improvements in QoL of APD patients [16-18]. To explain these discrepancies, it is necessary to take into consideration that our study is a cross-sectional study and the average treatment duration of the DAT in this population was approximately 3 years.

The prevalence of PD can be influenced not only by the incidence of the disease, the survival and age of the study population, and genetic and environmental factors, but also by the study methodology and the criteria applied for disease diagnosis [19]. In our study, we found a PD prevalence of 118.4 per 100,000 population. This prevalence is much lower than the prevalence ranging from 901 to 1500 patients with PD per 100,000 population found in three studies conducted in small geographic areas of Spain, using door-to-door methodology, and in an elderly population [20-22]. However, the prevalence found in our PARADISE study is slightly lower than the prevalence ranging from 161.5 to 277 per 100,000 population found in six other studies carried out in Spain [23-28]. These studies were also conducted in small geographic areas, two of which were population-based studies 
in patients with PD requiring health care services [24,25], and the other four determined the prevalence of PD by use/consumption of antiparkinsonian drugs [23,26-28]. In 2005, von Campenhausen et al. carried out a systematic literature search to identify studies on the prevalence and incidence of PD in European countries. These authors found a PD prevalence in Europe ranging from 65.6 to 12,500 per 100,000 population [29]. In 2014, Pringsheim et al. found a worldwide PD prevalence of 315 patients (95\% CI: 113-873) per 100,000 population in a meta-analysis that included all published studies of door-todoor surveys or random population samples with a physical examination by a health professional to confirm or exclude a diagnosis of PD [3].

Concerning the incidence of PD, we found a PD annual incidence of 9.4 per 100,000 population. In 2003, Twelves et al. carried out a systematic review and found 25 studies focused on the incidence of PD. The incidence ranged from 1.5 per 100,000 per year in China to 26 per 100,000 per year in the United Kingdom. All studies included in the review were methodologically different, but five were similar enough to perform a comparison. Four of them found a standardized incidence of 16 to 19 per 100,000 per year, but the fifth study, carried out in Italy, found an incidence of 8.4 per 100,000 population [30]. In the above-mentioned door-to-door study conducted in central Spain [20], in a population aged 65 to 85 and over years and adjusted to the standard European population, the average annual incidence rate for PD was 186.8 per 100,000 person-years. Notably, the $53.3 \%$ of the patients were detected through the screening and had not been diagnosed previously. This could explain why the prevalence and incidence rates from hospital-based studies are lower. In our hospital-based study, there was no age limit for recruitment. As previously mentioned, differences with our study could be explained by environmental or genetic factors, geographic distribution, differences in populations, or different methodological approaches, including diagnostic criteria.

This study has some limitations. The real prevalence of PD in Spain could be higher than the prevalence found in our study because there can be patients who have PD but have not yet been diagnosed. The only way to eliminate this bias would be to conduct population studies "door to door", in which specialists undertake the diagnosis in a selected sample of subjects. These types of studies are extremely expensive; thus, it is practically unviable to carry them out at national level. Moreover, as PD diagnosis is mainly clinical and neuroimaging testing were not required in the study to recruit patients, it is possible that patients currently diagnosed as having PD actually have another disorder under the category of parkinsonism, quite likely progressive supranuclear paralysis with predominant parkinsonism [31]. Although misdiagnosed patients are few, ranging from $5.9 \%$ [32] to $6.6 \%$ [33], this could have happened in our study.

Inaccuracy in PD diagnosis may also affect the assessment of the incidence of the disease. It has been published that specialists can make an erroneous initial diagnose of $\mathrm{PD}$ in $6 \%$ to $25 \%$ of the cases [32]. However, we should also consider that, although some patients can be diagnosed with $\mathrm{PD}$, they may have an alternative parkinsonian condition; the reverse can also occur. In the study of Schrag et al., performed in the primary care setting, $\geq 15 \%$ of patients initially diagnosed with PD finally did not meet PD criteria; by contrast, $19 \%$ of patients who should have been diagnosed with PD were not [34].

In addition, our prevalence and incidence data are limited to the Spanish public hospitals, which means the Spanish population being cared for by private centers has not been included in our study. Nevertheless, we consider that this patient population exclusion had little impact on the results obtained as only $3.8 \%$ of the Spanish population were cared in private centers when the study begun [35]. Finally, it is also important to consider that the institutionalized population and potential PD population not yet diagnosed or diagnosed but still at the primary care level or in transit to the neurologist's hospital have neither been included.

The strength of this study was the methodology used; the stratified random sampling that led to a selection of patients that represents the whole national territory; the large number of participating patients made it possible to obtain precise data with narrow 
confidence intervals; and the use of the validated objective tool CDEPA, which helped to identify APD patients.

\section{Conclusions}

In our study, the percentage of patients found with APD among those with PD cared for in hospitals of the Spanish National Healthcare System, and which is based on the neurologist's criteria, is $38.2 \%$. To the best of our knowledge, this is the first epidemiological study quantifying APD at the hospital level, including all types of neurology services in terms of specialization in PD. This prevalence is in concordance with that found by identifying patients with the screening tool CDEPA. Besides, the prevalence and the annual incidence of diagnosed PD found in this study is 118.4 and 9.4 per 100,000 population, respectively, which is lower than previously published. Conversely, we found a low percentage of APD patients receiving DAT, which would need further investigation.

Author Contributions: Authors' roles include but are not restricted to: Conceptualization, J.C.M.-C., Á.B., G.A. and J.M.A.; methodology, Á.B.; organization: Á.B. and G.A.; investigation: Á.B. and G.A.; data curation, J.C.M.-C., P.M.-M., A.B, G.A., M.R.L. and J.M.A.; writing—original draft preparation, Á.B.; writing-review and editing, J.C.M.-C., P.M.-M., Á.B., G.A., N.G., M.R.L. and J.M.A. All authors have read and agreed to the published version of the manuscript.

Funding: The design: study conduct, and financial support for the clinical study were provided by AbbVie. AbbVie participated in the interpretation of data, review, and approval of the publication. No honoraria or payments were made for authorship.

Institutional Review Board Statement: The study was conducted in accordance with ethical principles that have their origin in the Declaration of Helsinki. The study was approved by the Spanish Agency of Medicines and Medical Devices and the Ethics Committees of all the participant hospitals.

Informed Consent Statement: Informed consent was obtained from all subjects involved in the study.

Data Availability Statement: AbbVie is committed to responsible data sharing regarding the clinical studies we sponsor. This includes access to anonymized, individual and trial-level data (analysis data sets), as well as other information (e.g., protocols and clinical study reports), as long as the studies are not part of an ongoing or planned regulatory submission. This includes requests for clinical studies data for unlicensed products and indications. This clinical study data can be requested by any qualified researchers who engage in rigorous, independent scientific research, and will be provided following review and approval of a research proposal and statistical analysis plan (SAP) and execution of a data sharing agreement (DSA). Data requests can be submitted at any time and the data will be accessible for 12 months, with possible extensions considered. For more information on the process, or to submit a request, visit the following link: https:/ / www.abbvie.com/our-science/clinical-trials/clinical-trials-data-and-informationsharing/data-and-information-sharing-with-qualified-researchers.html.

Acknowledgments: We want to thank Ignacio Parra at Pivotal, S.L., for statistical analysis assistance, whose service was funded by AbbVie S.L.U. PARADISE Study Group (non-author contributors). Hospital de Guadalajara: Antonio Yusta, Jaime Hernández, Ignacio López-Zuazo, Ma Templo Andrés, M Jesús Sánchez; Hospital Río Carrión: Fuencisla Gutiérrez, Federico Iglesias, Sandra Jorge; Hospital Universitario de Canarias: Francisco Javier Carrillo, Mercedes Pueyo; Hospital San Pedro de La Rioja: Silvia Calvo, Ángel Martínez, Ignacio Hernando, Francisco José Julián, $\mathrm{M}^{\mathrm{a}}$ Eugenia Marzo, $\mathrm{M}^{\mathrm{a}}$ Belinda Matute, $\mathrm{M}^{\mathrm{a}}$ Ángeles López, Olga Blasco, María Gómez; Hospital Reina Sofía (Tudela): Antonio Oliveros; Hospital Álvarez Buylla: Vanesa de la Vega, Jimena González; Hospital Zumárraga: Marta Ruibal, Ander Olaskoaga; Fundación Jiménez Díaz: Javier del Val, Cicí Esmerali Feliz; Hospital Melilla: Clementina del Canto; Hospital Punta de Europa: M ${ }^{a}$ Luz Peinado, Mladenka Todorova, Rosario Gil; Hospital Marina Salud: Ángel Mateu, Natalia Giraldo, Jaime San Narciso; Hospital Virgen de la Victoria: Ma José Gómez, Francisco Pérez; Hospital Lozano Blesa: Sara Sánchez, Elena Bellosta; Hospital Arnau i Vilanova (Valencia): Caridad Valero, Pilar Solís, Macarena Bonet, María Boscá, Ana Pareja, Rafael Sánchez, Carlos Perla, Pablo López; Hospital Germans Trias i Pujol: Ramiro Álvarez, Dolores Vila, Lourdes Ispierto; Hospital Monforte de Lemos: Laura Ramos; Hospital Infanta Cristina (Badajoz): $\mathrm{M}^{\mathrm{a}}$ Rosa Velicia, Ana $\mathrm{M}^{\mathrm{a}}$ Roa; Hospital Alcorcón: Lidia Vela; Hospital Reina 
Sofía (Córdoba): M Teresa Cáceres; Hospital Pontevedra: Iria Cabo, José Ramón Rodríguez, Beatriz Canneti, Alfredo Puy, Ana Rodríguez, Ana Paula Suárez, Clara Domínguez; Hospital Royo Villanova: Alfredo López, Consuelo Ríos, Alba Velázquez, Ma José García, José Mª Pérez.

Conflicts of Interest: JC Martínez-Castrillo has received honoraria for speaking at meetings sponsored by AbbVie, Allergan, Bial, Boehringer, GSK, Krka, Merz, Ipsen, Italfarmaco, Lundbeck, Medtronic, TEVA, UCB, and Zambon; travel grants from AbbVie, Allergan, Bial, Italfarmaco, TEVA, UCB, Merz, Krka, and Zambón; research grants from AbbVie, Allergan, Merz, Italfarmaco, Lundbeck, $\mathrm{UCB}$, and Zambon; and has participated in advisory boards of AbbVie, Allergan, GSK, Bial, Merz, Merck, Boehringer, Ipsen, Italfarmaco, Lundbeck, UCB, and Zambon. P Martínez-Martín has received honoraria from Editorial Viguera and Takeda Pharmaceuticals for lecturing in courses; and from the International Parkinson and Movement Disorder Society (IPMDS) for management of the Program on Rating Scales. A. Burgos was an AbbVie employee prior to the writing of the article and may hold stock or stock options. G. Arroyo and N. García are AbbVie employees and may hold stock or stock options. MR Luquin has received honoraria for lecturing and advisory board from AbbVie, Lundbeck, UCB, and Italfarmaco and research grants from the European Commission and Instituto de Salud Carlos III. G. Arroyo is an employee of AbbVie. N. García is an employee of AbbVie and holds AbbVie stock or stock options. J.M. Arbelo has received honoraria from AbbVie, Zambon, Bial, and Teva.

\section{References}

1. Aarli, J.A.; Tarun, D.; Janca, A.; Muscetta, A. Neurological Disorders: Public Health Challenges; World Health Organization: Geneva, Switzerland, 2006.

2. GBD 2016 Parkinson's Disease Collaborators. Global, regional, and national burden of Parkinson's disease, 1990-2016: A systematic analysis for the Global Burden of Disease Study 2016. Lancet Neurol. 2018, 17, 939-953. [CrossRef]

3. Pringsheim, T.; Jette, N.; Frolkis, A.; Steeves, T.D. The prevalence of Parkinson's disease: A systematic review and meta-analysis. Mov. Disord. 2014, 29, 1583-1590. [CrossRef] [PubMed]

4. Nyholm, D. The rationale for continuous dopaminergic stimulation in advanced Parkinson's disease. Parkinsonism Relat. Disord. 2007, 13, S13-S17. [CrossRef] [PubMed]

5. Ejma, M.; Madetko, N.; Brzecka, A.; Guranski, K.; Alster, P.; Misiuk-Hojło, M.; Somasundaram, S.G.; Kirkland, C.E.; Aliev, G. The Links between Parkinson's Disease and Cancer. Biomedicines 2020, 8, 416. [CrossRef]

6. Lees, J.; Hardy, J.; Revesz, T. Parkinson's disease. Lancet 2009, 373, 2055-2066. [CrossRef]

7. Benito-León, J.; Bermejo-Pareja, F.; Rodríguez, J.; Molina, J.A.; Gabriel, R.; Morales, J.M.; Neurological Disorders in Central Spain (NEDICES) Study Group. Prevalence of PD and other types of parkinsonism in three elderly populations of central Spain. Mov. Disord. 2003, 18, 267-274. [CrossRef] [PubMed]

8. Ministerio de Sanidad, Consumo y Bienestar Social, Catálogo Nacional de Hospitales (National Hospitals Catalog). 2016. Available online: https://www.mscbs.gob.es/ciudadanos/prestaciones/centrosServiciosSNS/hospitales/home.htm (accessed on 16 November 2021).

9. Levy, P.S.; Lemeshow, S. Stratification and Stratified Random Sampling. In Sampling of Populations: Methods and Applications; Balding, D.J., Cressie, N.A.C., Fitzmaurice, G.M., Goldstein, H., Molenberghs, G., Scott, D.W., Smith, A.F.M., Tsay, R.S., Weisberg, S., Eds.; John Wiley \& Sons Inc.: New York, NY, USA, 2013; p. 10158-0012.

10. Martinez-Martin, P.; Kulisevsky, J.; Mir, P.; Tolosa, E.; Garcia-Delgado, P.; Luquin, M.R. Validation of a simple screening tool for early diagnosis of advanced Parkinson's disease in daily practice: The CDEPA questionnaire. NPJ Parkinson's Dis. 2018, 4, 20. [CrossRef]

11. Luquin, M.R.; Kulisevsky, J.; Martinez-Martin, P.; Mir, P.; Tolosa, E.S. Consensus on the Definition of Advanced Parkinson's Disease: A Neurologists-Based Delphi Study (CEPA Study). Parkinson's Dis. 2017, 2017, 4047392. [CrossRef]

12. MCharlson, E.; Pompei, P.; Ales, K.L.; MacKenzie, C.R. A new method of classifying prognostic comorbidity in longitudinal studies: Development and validation. J. Chronic Dis. 1987, 40, 373-383. [CrossRef]

13. Jenkinson, C.; Fitzpatrick, R.; Peto, V.; Greenhall, R.; Hyman, N. The PDQ-8: Development and validation of a short-form parkinson's disease questionnaire. Psychol. Health 1997, 12, 805-814. [CrossRef]

14. Hoehn, M.M.; Yahr, M.D. Parkinsonism: Onset, progression and mortality. Neurology 1967, 17, 427-442. [CrossRef] [PubMed]

15. Fasano, A.; Fung, V.S.C.; Lopiano, L.; Elibol, B.; Smolentseva, I.G.; Seppi, K.; Takáts, A.; Onul, K.; Parra, J.C.; Bergmann, L.; et al. Characterizing advanced Parkinson's disease: OBSERVE-PD observational study results of 2615 patients. BMC Neurol. 2019, 19, 50. [CrossRef] [PubMed]

16. Olanow, C.W.; Kieburtz, K.; Odin, P.; Espay, A.J.; Standaert, D.G.; Fernandez, H.H.; Vanagunas, A.; Othman, A.A.; Widnell, K.L.; Robieson, W.Z.; et al. Continuous intrajejunal infusion of levodopa-carbidopa intestinal gel for patients with advanced Parkinson's disease: A randomised, controlled, double-blind, double-dummy study. Lancet Neurol. 2014, 13, 141-149. [CrossRef] 
17. Katzenschlager, R.; Poewe, W.; Rascol, O.; Trenkwalder, C.; Deuschl, G.; Chaudhuri, K.R.; Henriksen, T.; Laar, T.V.; Spivey, K.; Vel, S.; et al. Apomorphine subcutaneous infusion in patients with Parkinson's disease with persistent motor fluctuations (TOLEDO): A multicentre, double-blind, randomised, placebo-controlled trial. Lancet Neurol. 2018, 17, 749-759. [CrossRef]

18. Deuschl, G.; Schade-Brittinger, C.; Krack, P.; Volkmann, J.; Schäfer, H.; Bötzel, K.; Daniels, C.; Deutschländer, A.; Dillmann, U.; Eisner, W.; et al. A randomized trial of deep-brain stimulation for Parkinson's disease. N. Engl. J. Med. 2006, 355, 896-908. [CrossRef]

19. Elbaz, A.; Carcaillon, L.; Kab, S.; Moisan, F. Epidemiology of Parkinson's disease. Rev. Neurol. 2016, 172, 14-26. [CrossRef]

20. Benito-Leon, J. Epidemiology of Parkinson's disease in Spain and its contextualisation in the world. Rev. De Neurol. 2018, 66, 125-134.

21. Bergareche, A.; De La Puente, E.; de Munain, A.L.; Sarasqueta, C.; De Arce, A.; Poza, J.J.; Martí-Massó, J.F. Prevalence of Parkinson's disease and other types of Parkinsonism. A door-to-door survey in Bidasoa, Spain. J. Neurol. 2004, 251, 340-345. [CrossRef]

22. Clavería, L.E.; Duarte, J.; Sevillano, M.D.; Pérez-Sempere, A.; Cabezas, C.; Rodríguez, F.; de Pedro-Cuesta, J. Prevalence of Parkinson's disease in Cantalejo, Spain: A door-to-door survey. Mov. Disord. 2002, 17, 242-249. [CrossRef]

23. Sanz, M.T.A.; Rueda, J.J.V. The estimation of the prevalence of Parkinson's disease in Navarra. An epidemiological study on the consumption of antiparkinsonian drugs. Rev. Española De Salud Pública 1995, 69, 479-485.

24. Martínez-Pérez, J.A.; Ortiz-García, R.; González-Zerega, A.; López-Gosling, I.; Guzmán, A.; Dragomir, E. Epidemiología del parkinsonismo en el Área de Salud de Guadalajara. Semerge 2014, 40, 305-312. [CrossRef] [PubMed]

25. Errea, J.M.; Ara, J.R.; Aibar, C.; de Pedro-Cuesta, J. Prevalence of Parkinson's disease in lower Aragon, Spain. Mov. Disord. 1999, 14, 596-604. [CrossRef]

26. Abasolo-Osinaga, E.; Abecia-Inchaurregui, L.C.; Fernandez-Diaz, E.; Barcenilla-Laguna, A.; Banares-Onraita, T. The prevalence and pharmacological cost of Parkinson's disease in Spain. Rev. De Neurol. 2006, 43, 641-645.

27. Criado-Alvarez, J.J.; Romo-Barrientos, C.; Martinez-Hernandez, J.; Gonzalez-Solana, I. Use of antiparkinsonian agents in Castilla-La Mancha. Estimate of prevalence of Parkinson disease. Rev. De Neurol. 1998, 27, 405-408.

28. Martinez-Suarez, M.M.; Blazquez-Menes, B. Estimation of the prevalence of Parkinson's disease in Asturia, Spain. A pharmacoepidemiological study of the consumption of antiparkinson drugs. Rev. De Neurol. 2000, 31, 1001-1006.

29. Twelves, C.; Perkins, K.S.M.; Counsell, C. Systematic review of incidence studies of Parkinson's disease. Mov. Disord. 2003, 18, 19-31. [CrossRef] [PubMed]

30. Newman, E.J.; Grosset, K.A.; Grosset, D.G. Geographical difference in Parkinson's disease prevalence within West Scotland. Mov. Disord. 2009, 24, 401-406. [CrossRef]

31. Alster, P.; Madetko, N.; Koziorowski, D.; Friedman, A. Progressive Supranuclear Palsy-Parkinsonism Predominant (PSP-P)-A Clinical Challenge at the Boundaries of PSP and Parkinson's Disease (PD). Front. Neurol. 2020, 11, 180. [CrossRef] [PubMed]

32. Kim, H.M.; Leverenz, J.B.; Burdick, D.J.; Srivatsal, S.; Pate, J.; Hu, S.C.; Zabetian, C.P. Diagnostic Validation for Participants in the Washington State Parkinson Disease Registry. Parkinson's Dis. 2018, 2018, 3719578. [CrossRef]

33. National Collaborating Centre for Chronic Conditions (UK). Parkinson's Disease: National Clinical Guideline for Diagnosis and Management in Primary and Secondary Care; Royal College of Physician: London, UK, 2006.

34. Schrag, A.; Ben-Shlomo, Y.; Quinn, N. How valid is the clinical diagnosis of Parkinson's disease in the community. J. Neurol. Neurosurg. Psychiatry 2002, 73, 529-534. [CrossRef]

35. Memoria 2014 MUGEJU, Mutualidad General Judicial. Available online: http://www.mugeju.es/es/includes/documentos/ mugeju/mugeju2014.pdf (accessed on 16 November 2021). 